\title{
Erratum to: \\ Bioeconomy: Shaping the Transition to a Sustainable, Biobased Economy
}

Iris Lewandowski

\section{Erratum to:}

\section{Chapters 5, 6, 7 and 8 in:}

I. Lewandowski (ed.), Bioeconomy, https://doi.org/10.1007/978-3-31968152-8

The original online version of this book was inadvertently published with incorrect author details in the chapters 5, 6, 7 and 8. In the original publication, the Editor's name was inadvertently presented as the author of these chapters. This has now been amended with the correct authorship details.

The updated online versions of these chapters can be found at

https://doi.org/10.1007/978-3-319-68152-8_5

https://doi.org/10.1007/978-3-319-68152-8_6

https://doi.org/10.1007/978-3-319-68152-8_7

https://doi.org/10.1007/978-3-319-68152-8_8

https://doi.org/10.1007/978-3-319-68152-8 